\title{
Uma ideia sem lugar: notas sobre a invenção do Brasil moderno em A máquina de madeira, de Miguel Sanches Neto
}

\section{A misplaced idea: notes on the invention of modern Brazil in A máquina de madeira, by Miguel Sanches Neto}

Márcio Matiassi Cantarin

Universidade Tecnológica Federal do Paraná (UTFPR), Curitiba, Paraná, Brasil. cantarin@gmail.com

Rogério Caetano de Almeida

Universidade Tecnológica Federal do Paraná (UTFPR), Curitiba, Paraná, Brasil. rogalmeida01@hotmail.com

Marcelo Fernando de Lima

Universidade Tecnológica Federal do Paraná (UTFPR), Curitiba, Paraná, Brasil. marcelofernandodelima@yahoo.com.br

Resumo: Este trabalho objetiva analisar o romance $A$ máquina de madeira (2012), de Miguel Sanches Neto, numa perspectiva que o inclui no rol de "novo romance histórico brasileiro". O livro resgata, via ficção, a história do padre Francisco João de Azevedo (1814 - 1880), inventor de uma máquina taquigráfica que teria servido de protótipo para o desenvolvimento da primeira máquina de escrever. A partir da constatação de que o Brasil do $2^{\circ}$ Império possui uma fragilidade em suas estruturas políticas, econômicas, ideológicas e sociais, a despeito de a política oficial de D. Pedro II pregar o progresso e desenvolvimento da 
nação, verifica-se o espelhamento e a reverberação dessas fragilidades na contemporaneidade. Assim, pensar esse passado ajuda a lançar luzes sobre algumas mazelas do pensamento nacional que tendem a se perpetuar, ainda que sob novas roupagens. Paradoxalmente, constata-se que o lugar inexistente e as ideias sem lugar do século XIX caracterizam a reflexão crítica do pensamento brasileiro contemporâneo, portanto nossa existência.

Palavras-chave: metaficção histórica; narrativa brasileira contemporânea; tecnologia.

Abstract: This work aims at analyzing the novel $A$ máquina de madeira (2012), by Miguel Sanches Neto, in a perspective which includes it in the "new Brazilian historical novels". The book reviews, through fiction, the story of Father Francisco João de Azevedo (1814 - 1880), the inventor of a machine for tachygraphy, which is believed to have been the prototype to the development of the first typewriter. Based on the observation of frailties in political, economic, ideological and social structures in Brazil during the Second Empire, despite the D. Pedro II's official policy of progress and development of the nation, we verify that contemporaneity mirrors and reverberates such weaknesses. Therefore, reflecting on this past helps to shed a light on some of the problems of national thinking that tend to be perpetuated, even if in new shapes. Paradoxically, we verify that the nonexistent place and the ideas without place in the nineteenth century mark the critical reflection on the contemporary Brazilian thinking and, therefore, on our existence.

Keywords: historical metafiction; brazilian contemporary narrative; technology.

Recebido em 27 de fevereiro de 2015.

Aprovado em 15 de julho de 2015. 
Em seu romance $A$ máquina de Madeira (2012), o paranaense Miguel Sanches Neto resgata, via ficção, a história do padre Francisco João de Azevedo (1814 - 1880), inventor de uma máquina taquigráfica que teria servido de protótipo para o desenvolvimento da primeira máquina de escrever. Alguns dos temas fundamentais para a cultura brasileira deste início de século são apresentados e discutidos pelo romance em maior ou menor grau, a saber: o que é modernidade e pós-modernidade; a relação entre arte e realidade; a identidade do brasileiro; o papel da mestiçagem cultural para a história do país; a desigualdade sntor. Após ter logrado grande sucesso com a exibição de sua máquina taquigráfica em uma exposição na província, Azevedo desembarca com seu invento no Rio de Janeiro, em 1861, a fim de apresentar-se na Exposição Nacional na presença do imperador D. Pedro II. A pretensão do padre era a de alcançar participar da Exposição de Londres, que aconteceria em 1862, onde poderia firmar parcerias para o aperfeiçoamento da máquina, sua fundição em ferro (uma vez que o protótipo era confeccionado em madeira, como anuncia o título da obra) e produção em escala comercial. Com isso, a máquina poderia se popularizar para que os sermões fossem transcritos ainda no púlpito das igrejas e não se perdessem, mas também vislumbrava sua máquina como ferramenta nas redações de jornais, por exemplo.

A despeito de ter sido premiado na exposição da corte brasileira, a máquina não seguiria para Londres por dificuldades de acomodação na embarcação e pelo pouco espaço destinado aos produtos brasileiros no evento europeu. Anos mais tarde, persistindo ainda em seu intento, o projeto da máquina acaba sendo roubado por investidores norteamericanos. Logo depois fica sabendo que a máquina de escrever passou a ser produzida comercialmente. Ao inventor brasileiro resta o ostracismo até sua morte. Entrementes, por meio de uma série de analepses, tomamos conhecimento de fatos da vida do protagonista, seu percurso como seminarista, o caso amoroso com uma escrava do qual resultou uma filha ilegítima e outras histórias de fundo - todas elas alegorizam o protagonista como um sujeito fora do lugar em sentido histórico, filosófico, religioso e científico.

Desde que foi dada à luz, em função dessa "base real" sobre a qual se erige, a obra recebeu o selo de "romance histórico", pelo que pode ser analisada pelo prisma da chamada metaficção historiográfica, para usar a terminologia proposta por Linda Hutcheon (2002). Infrutífero nas 
análises desse tipo de obra tentar simplesmente separar o fato histórico do ficcional; aliás, enquanto ficção, um desafio inerente ao romance histórico realista é justamente fazer com que se esqueça de tal dilema. Ainda que possível - ignoradas as fronteiras permeáveis entre real e ficcional - não passaria de mero exercício lúdico, ou um exercício estilístico que registre uma eventual pesquisa histórica e/ou a marcação de um estilo. Assim, interessa aqui, trazer ao centro do debate a problematização de aspectos históricos concernentes ao período em que a narrativa se desenvolve, refletindo sobre a fragilidade das estruturas políticas, econômicas e sociais do país gestado pelo imaginário popular, e estabelecer algumas relações possíveis com a contemporaneidade numa espécie de espelhamento, lançando luzes sobre algumas mazelas do pensamento nacional que tendem a se perpetuar. Desta forma, espera-se, ao fim, demonstrar o quanto alguns dos embates mais sérios de nossa época não passam de desdobramentos, quando não de repetição, dos entraves políticos e/ou ideológicos enfrentados pelo padre-inventor há mais de 150 anos.

Assim sendo, a metaficção historiográfica de Miguel Sanches Neto dialoga, relê e corrobora a reflexão feita por Roberto Schwarz em As ideias fora do lugar (SCHWARZ, 2005, p. 59-85). Neste trabalho mais abrangente sobre o Brasil do século XIX, temos pontuadas muitas das características que despontam na narrativa: enquanto a Europa desenvolve os ideais de Liberdade, Igualdade e Fraternidade, aqui o escravismo é uma instituição; enquanto lá se desenvolve a universalidade de princípios, aqui vige a prática geral do favor; por último, as ideias libertárias não poderiam se desenvolver num país agrário com grandes latifúndios dependente do trabalho escravo. Assim sendo, as ideias liberais europeias são "ornamentadas", nas palavras de Schwarz, por uma elite dominante e impossibilitadas pelo escravismo e pelo favor. Tais ideias fora do lugar têm como contraponto a industrialização das nações europeias.

Ainda que pouco contestatória/revolucionária uma vez que não faz uso da paródia ou da sátira ou ainda da carnavalização, preferindo manter-se no terreno mais seguro de uma textualidade com referentes históricos documentados, a narrativa de Sanches Neto manifesta evidente desejo de realizar uma leitura crítica da história, possibilitando outro viés para a leitura daqueles eventos que foram registrados tão somente pela visão hegemônica. Assim, se Machado de Assis ironizava toda a 
sociedade de sua época com elementos da sátira menipeia ${ }^{1}$, a revisitação de nosso século XIX, na narrativa de Sanches Neto, é circunspecta e, por isso mesmo, gera uma sensação de estranheza similar a que Freud $^{2}$ desenvolve. Tal mal-estar está associado ao fato de que os problemas do Brasil no século XIX se reverberam inevitavelmente na contemporaneidade.

\section{Outrora é agora?}

Se for verdadeira a assertiva de que a literatura é uma leitora privilegiada dos signos da história (MILTON, 1992), então, nesse romance, o autor escancara didaticamente (em que pese o prejuízo que esse pendor retórico-reflexivo de Sanches Neto cause ao andamento e forma de seu romance) a falácia que configurou o reinado de D. Pedro II, tido como um dos períodos de maior empreendedorismo que o Brasil conhecera até então. Irá cumprir, de algum modo, aquela função desmistificadora da história, tão cara ao gênero no qual se inscreve.

A desconstrução perpassa todo o romance na medida em que ao discurso de progresso e desenvolvimentismo que chega ao Nordeste sobre a Corte, se contrapõe o que a personagem presencia em uma cidade plena de contrastes, que mimetizava uma Paris idealizada na Rua do Ouvidor, mas jogava seus dejetos no mar. Referimo-nos a uma Paris idealizada pela província, pois as modificações de Georges-Eugène Haussmann no traçado urbano se iniciam em 1852 e as necessárias reformas no problemático sistema de esgoto foram levadas a cabo por ele exatamente a partir de 1861, ano em que nosso Padre chega ao Rio de Janeiro para expor sua tão estrambótica máquina de madeira.

Enquanto para alguns, notadamente as senhoras, "urgia viver em Paris", para outros (os trabalhadores da cidade, representados pelo carroceiro que transportou o padre e seu invento assim que desembarcou na corte) "Urgia mesmo melhorar as vias públicas, pois até a rua central, por onde passavam os príncipes, se encontrava cheias de pedras soltas" (SANCHES NETO, 2012, p. 19). No entanto, as melhorias urbanas

\footnotetext{
${ }^{1}$ Ver Enylton de Sá Rego.

${ }^{2}$ Segundo o vienense, o estranho tem a ver com o que é conhecido ou familiar e foi esquecido pelo consciente através do recalque que, por algum motivo - lembrança, associação ou mesmo de maneira abrupta -, volta ao centro da consciência.
} 
proporcionadas pelas reformas de Haussmann em Paris possuem uma perspectiva bem diferente da idealização provinciana que se faz da Europa: "Haussmann denomina a si mesmo de artista demolidor'. [...] Entretanto, [a reforma urbana] provoca nos parisienses um estranhamento em relação à sua cidade. Nela não se sentem mais em casa. Começam a tomar consciência do caráter desumano da grande cidade" (BENJAMIN, 2006, p. 49). Havia aqui no Brasil, no entanto, um consenso entre as senhoras da nobreza preocupadas com a moda, perfumes e futilidades afins, e aquele trabalhador, preocupado com a precariedade da iluminação pública em uma cidade com tantos ladrões: "tudo que é bom vem de fora" (SANCHES NETO, 2012, p. 18), aí inclusos os membros da família real e a mão de obra dos escravos africanos. Tal perspectiva se refere ao brasileiro "desterrado em nossa própria terra - importamos todos os nossos valores" (SCHWARZ, 2005, p. 61). O brasileiro, então, é, no século XIX, uma impossibilidade. O homem é fora do lugar porque, também, fora do tempo em que vive e das ideias difundidas nesse período.

E é a partir das palavras do carroceiro que Padre Azevedo encetará seu discurso sobre homens que eram "prisioneiros do momento" em oposição aos homens das ciências, aos inventores. Estes, imersos em um sem número de dificuldades, uma vez que viviam em um país em que aqueles eram absoluta maioria, gente, por assim dizer, obtusa, apenas interessada naquilo que as atingia diretamente, em contraste com um visionário preocupado com o progresso e o bem comum. Deste ponto, constata-se que "Tudo era dificuldade para quem ousava contrariar a pasmaceira do país" (SANCHES NETO, 2012, p. 14) e tem o triste insight de que seu invento/ideia já desembarcara defunto na corte. As considerações que a personagem vai tecendo ao longo de toda a obra lhe conferem o status de um visionário em um país de ignorantes. Ironicamente, no final da vida, esse visionário se mostrará tão ingênuo quanto uma criança que tem seu doce roubado. Padre Azevedo vislumbra um país sem visadas ao progresso, situando-se num espaço que ainda não era exatamente seu, dadas as circunstâncias da dominação europeia nos planos das ideias e da economia. Então, o padre é uma sinédoque do país, ao mesmo tempo, órfão e recém-nascido; tal qual seu povo, sem lugar.

O padre Francisco João de Azevedo pode bem ser enquadrado como uma personagem periférica ou "ex-cêntrica", desprezada pelas narrativas hegemônicas. Para Hutcheon (2002, p. 103), a possibilidade de recuperar tais personagens constitui uma das principais marcas do romance histórico contemporâneo. 
Quando chega ao local da Exposição, fica mais gritante esse deslocamento, o fora-de-lugar, tanto do invento em si quanto das ideias do inventor ou dele próprio, sempre pouco à vontade no ambiente da Corte (vide o constrangimento que passa ao ir a uma casa de banhos). O diálogo com outro expositor deixa isso bastante claro, ao passo que também revela para qual direção fluem os ventos progressistas que emanam da corte:

- As máquinas vão ficar no térreo, nas galerias laterais ele explicou ao padre.

- Há outras máquinas para escrever? - ele se alarmou.

- Não, não, para escrever não - Rischen ria -, apenas máquinas que ajudam os homens a produzir mais. (SANCHES NETO, 2012, p. 23)

Os (des)interesses da nação estão associados à boa e velha política do favor. A inadequação da moderna máquina àquele ambiente ficará mais destacada quando Rischen consegue, mediante suborno, uma cadeira em estilo rococó para que Azevedo pudesse colocá-la para operar. A dificuldade em definir o valor, natureza e o local que o invento deveria ocupar na exposição reforça essa ideia de deslocamento, o que fará com que Rischen resuma lapidarmente o imbróglio: "-Um inventor pertence a um país que ainda não existe" (SANCHES NETO, 2012, p. 27). A marca do conservadorismo tacanho é tão latente, que o invento talvez seja visto apenas quando colocado diante de uma cadeira que represente a tradição, ou, o antigo, o arcaico, o atrasado.

Diante de tal constatação, o ânimo do protagonista, com vistas ao desenvolvimento do país, segue oscilando. A fé de Rischen na substituição do país de então por um mais moderno (SANCHES NETO, 2012, p. 28) só em esparsos momentos encontra eco no espírito do padre que, em geral, não consegue admitir que a semente do progresso encontrasse terreno fértil em uma nação com uma identidade tão precária e com tamanhos contrastes. Não seria, no entanto, um preconceito considerar nosso país atrasado? Alfredo Bosi coloca a questão em termos de temporalidade: 
Quem já não ouviu dizer em tom de escárnio que as elites brasileiras se acreditam engolfadas no pós-moderno sem ter sequer atravessado a plena modernidade? As burguesias periféricas continuariam então sofrendo de um incurável provincianismo no momento mesmo em que afetam acertar o passo com os centros do Primeiro Mundo. (BOSI, 1996, p. 361).

E direciona tal discussão para questões do pensamento contemporâneo brasileiro:

A petrificação do conceito de colônia não seria responsável por essa obsessão do descompasso que às vezes empana a nitidez do olhar? Metrópole e colônia: haveria sempre e forçosamente duas linhas temporais paralelas - uma, longa, que já fez um percurso considerável em direção ao desenvolvimento, merecendo, portanto, o selo da modernidade, e a outra, mais curta, cujo ritmo lento a impediria de alcançar jamais a extensão da primeira? (BOSI, 1996, p. 361).

Então, a civilização europeia, tão inalcançável aos brasileiros, coloca-nos como bárbaros: a oposição civilização versus barbárie, que constituía entrave ao progresso científico-tecnológico e moral do Brasil parecia longe de uma solução plausível, uma vez que a crendice em pajelanças e não na ciência grassavam pelo país, afora outras práticas que contribuíam para mantê-lo em seu estágio de trevas em relação à Europa, como a utilização de sanguessugas nas práticas medicinais ou o sistema de tigres (baldes de madeira com os quais toda noite os escravos transportavam os dejetos das casas para serem lançados ao mar). "Sistema de esgoto móvel praticado no Brasil", como define, sarcasticamente, Mister Stein, um importador de produtos, que vai além:

Se dependesse do que se produzia aqui, o país ficaria reduzido a hábitos praticamente selvagens. Não se inventa uma revolução industrial da noite para o dia. E o Brasil ainda vivia na mais escura das noites, e muito tempo seria necessário para que se fizesse dia nesses malditos trópicos (SANCHES NETO, 2012, p. 54). 
A colocação de Mister Stein, no entanto, desconsidera que, em outra perspectiva, a do explorado, ele pode ser visto como o colonizador que, apesar de enriquecer na colônia, sempre a rebaixa numa comparação injusta com a Europa, afinal, conforme Benjamin (Op. Cit.), os esgotos de Paris ainda circulam em céu aberto e mal são recolhidos em 1861. Assim, o Brasil é um país bárbaro na perspectiva do europeu por ser parte da América. Se os ideais europeus eram muito mais avançados do que os dos trópicos, que os copiavam, a urbe, até então, não diferia muito. Paris não diferia muito da Paris medieval.

Em outra perspectiva, a própria ideia da exposição como "força civilizadora" (SANCHES NETO, 2012, p. 49), ainda que sirva apenas para civilizar nossas práticas agrícolas, não desperta grande entusiasmo no padre que já percebera que a passagem da barbárie à civilização aconteceria na transição da madeira para o ferro como base de nossos produtos e bens de consumo (SANCHES NETO, 2012, p. 43). Mas o Brasil permanecia longe dessa realidade. Enquanto importava o aço (já manufaturado, obviamente) da Inglaterra, nossos modos de extração de minérios em Minas Gerais eram ainda bastante primitivos, "lembrando que nossa indústria está na primeira infância e perde espaço para os países vizinhos" (SANCHES NETO, 2012, p. 117).

Apesar do esforço dos expositores e da propaganda governamental para mostrar a pujança da nascente indústria nacional, a imprensa e qualquer um com alguma acuidade intelectual podia perceber a falácia que era a Exposição, escancarada em um protesto que mostrava "OS VERDADEIROS PRODUTOS DA INDÚSTRIA NACIONAL" (SANCHES NETO, 2012, p. 116): correntes para prender os escravos e a famigerada máscara de folha de flandres. Tanto que os produtos manufaturados aqui e escolhidos para representar o Brasil na Exposição Universal em Londres não teriam por lá utilidade prática, servindo apenas para mostrar aos ingleses a imagem do Brasil: "selvagem e pujante". Desta feita, por exemplo, é que as panelas de pedra-sabão feitas em Minas Gerais não serviriam para nada: "Pena que não se pudesse preparar lá um frango com quiabo, pois é para essa culinária que elas existem" (SANCHES NETO, 2012, p. 134). Novamente: o Brasil, no século XIX, é o local onde viceja uma forte economia agrária de subsistência, com ciclos de exportação para apenas alguns produtos, a cana-de-açúcar e posteriormente o café são os exemplos acabados disso, e, para acentuar o problema, território em que tudo se sustenta nos ombros dos escravos. A manufatura escrava é o eixo dessa complexa engrenagem. 
Para além de "ferramentas de motor humano" (machados, foices, enxadas) seguia para a Exposição londrina o grande orgulho do imperador, uma coleção de mais de 300 amostras de madeira. A visão de que a madeira era o bem mais precioso que poderia haver no país faz com que Azevedo vislumbre que seu invento fosse, afinal, menos valorizado por sua função que pelo material de que era feito: Jacarandá (SANCHES NETO, 2012, p. 84).

De volta ao Recife, já em 1871, num Pernambuco que exaurira suas florestas, consumindo-as nos engenhos de açúcar, Azevedo se depara com um anúncio de venda de madeira da Suécia. Em breve sequer a madeira seria fonte de riqueza por aqui, ainda mais que tudo estava sendo substituído pelo ferro, muito mais duradouro (SANCHES NETO, 2012, p. 167-8). Para Walter Benjamin, a partir do momento em que se utiliza o ferro na construção das "passagens", essa "recente invenção do luxo industrial", temos uma mudança na relação do homem com a cidade e a tecnologia:

\begin{abstract}
Pela primeira vez na história da arquitetura, surge com o ferro um material de construção artificial. Ele vai passar por uma evolução cujo ritmo se acelera ao longo do século. Esta recebe o impulso decisivo quando se evidencia que a locomotiva, objeto de experimentos desde o final dos anos vinte, só poderia ser utilizada sobre trilhos de ferro. $\mathrm{O}$ trilho torna-se a primeira peça de ferro moldado, precursor da viga de ferro. Evita-se o ferro em construções residenciais, mas é utilizado em passagens, pavilhões de exposição, estações de trem - construções que serviam para fins transitórios (BENJAMIN, 2006, p. 40).
\end{abstract}

No Brasil daquele momento, mesmo em uma província distante da corte como a de Pernambuco, as fundições já detinham a técnica para não precisarem mais importar as peças manufaturadas. É o momento em que se evidencia um problema crônico da política econômica nacional do período - a subserviência de ideias:

...reclamou [o dono de uma fundição no Recife] da dificuldade de importar aço; e da lei que facilitava a vinda de máquinas do exterior, com a desculpa de estimular a agricultura do país. Isso estava acabando com as fundições. Pagavam impostos para o aço, mas quem comprava as máquinas prontas tinha todo o incentivo. 
- Um engenho a vapor vindo da Europa é mais barato do que o que produzimos aqui (SANCHES NETO, 2012, p. 171).

Outro excerto que se pretende exemplar na medida em que ironiza com acidez a subserviência mental do Brasil(eiro) em relação à Europa aparece em uma conversa informal do padre Azevedo com Frederico Albuquerque quando este censura amigavelmente a desordem das plantas na horta do padre ao dizer que: " - Um jardim é uma das formas de praticar a civilização” (SANCHES NETO, 2012, p. 178). E a conversa chega ao ápice quando Albuquerque revela que os administradores dos cemitérios tupiniquins estavam a importar da Europa ciprestes e chorões, árvores verdadeiramente fúnebres, que fariam nossos cemitérios perderem a cor e exuberância das mangueiras, ganhando um tom de meditação e sofrimento bem mais apropriado.

Em seu jardim, padre Azevedo possuía um limoeiro que não frutificava até que alguém lhe diz que é necessário cravar metal em seu tronco para estimular a produção dos frutos. Seu limoeiro produz o fruto em excesso a partir de então. Seria uma marca de conhecimento técnico, vindo do exterior (um japonês)? Ou alguma alusão ao fato de que em um território tão hostil só sobrevive quem também o é? “- Meu método de jardinagem não é de fato civilizado - ", (SANCHES NETO, 2012, p. 179) nos responde o padre.

$\mathrm{O}$ arremate de toda a tortuosa reflexão que Azevedo empreende acerca do progresso do Brasil é a constatação de que, afinal, depois de tanto esforço e percalços, e depois de seu invento ter sido roubado e produzido comercialmente pela norte-americana Remington, "A máquina não fora um sonho, só estava fora das possibilidades locais" (SANCHES NETO, 2012, p. 192), o que faz boa amálgama com aquela frase de Rischen: “ - Um inventor pertence a um país que ainda não existe" (SANCHES NETO, 2012, p. 27), ambas eximindo de culpa o inventor pelo fracasso do invento, afinal era o país que ainda não estava preparado. As reflexões de padre Azevedo não são novidadeiras. Seria o país de outrora o mesmo de agora? Distamos tanto da Europa e da América do Norte em ideias e tecnologia? 


\section{Máquinas de madeira contemporâneas: um ontem que ainda é agora}

A velha premissa do romance histórico tradicional (scottiano) de trazer as glórias do passado "en cuanto que plasmaba la evolución del pueblo (...) hasta llegar al presente" (LUKÁCS, 1977, p. 371), não se aplica a esta narrativa de Sanches. Para Antônio R. Esteves, "A falta de perspectivas claras para o futuro pode levar o brasileiro a mergulhar em seu passado, mas esse mergulho pode não ser somente mera fuga. Pode-se, também, tentar buscar no passado tanto explicações coerentes para o presente em crise, quanto soluções que ajudem a superar a crise do momento histórico contemporâneo" (ESTEVES, 2010, p. 66). As crises com o passado, com o presente e com o futuro para o brasileiro e, em geral, para o latino-americano, concertam com as crises que esse homem fora de lugar traz ao europeu eurocêntrico:

A maior contribuição da América Latina para a cultura ocidental vem da destruição sistemática dos conceitos de unidade e de pureza: estes dois conceitos perdem o contorno exato de seu significado, perdem seu peso esmagador, seu sinal de superioridade cultural, à medida que o trabalho de contaminação dos latino-americanos se afirma, se mostra mais e mais eficaz. A América Latina institui seu lugar no mapa da civilização ocidental graças ao movimento de desvio da norma, ativo e destruidor, que transfigura os elementos feitos e imutáveis que os europeus exportavam para o Novo Mundo. Em virtude do fato de que a América Latina não pode mais fechar suas portas à invasão estrangeira, não pode tampouco reencontrar sua condição de "paraíso", de isolamento e de inocência, constata-se com cinismo que, sem essa contribuição, seu produto seria mera cópia - silêncio -, uma cópia muitas vezes fora de moda, por causa desse retrocesso imperceptível no tempo, de que fala Lévi-Strauss. [...] O silêncio seria a resposta desejada pelo imperialismo cultural, ou ainda o eco sonoro que serve para apertar mais os laços do poder conquistador. Falar, escrever, significa: falar contra, escrever contra. (SANTIAGO, 2000, p. 16-17) 
Os problemas da falta de lugar, da falta de ideias próprias, da falta de um pensamento progressista efetivo, como demonstra Silviano Santiago, são os elementos de insatisfação (e/ou submissão) nos trópicos e esta traz, na perspectiva do crítico, uma escolha para o artista - submeterse à "cultura da metrópole" ou "assinalar os elementos que marcam sua diferença" em relação ao outro. Em A máquina de madeira vemos as duas perspectivas numa espécie de tensão dialética, permeada pelas falas e ações do padre e de outras personagens e pela própria relação com a história.

Segundo Letícia Malard (1996, p. 144), um dos riscos que esse tipo de romance assume é a tendência de mitificar/idealizar personagens ou acontecimentos históricos, em particular aqueles que se rebelaram e foram vencidos. Apesar da simpatia a que o leitor é levado a ter pela figura do desventurado padre, que pode beirar a piedade, Sanches parece estar longe de mitificar o protagonista de seu romance. Antes, a par desse sentimento de piedade - que não se adequa bem à figura de herói que fosse mitificado - salta aos olhos do leitor a figura do homem esmagado, também pelo sistema, como por uma espécie de debilidade moral da personagem, sentimento de culpa e autocomiseração cristãs (vide a resignação estoica de Azevedo na ocasião do roubo de seu projeto por empresários norte-americanos). Tal resignação, no entanto, é uma forma de resistir. O padre está lá, de alguma forma e, roubado que é, não deixa de existir. Miguel Sanches Neto, escritor latino-americano, fala contra, escreve contra.

Neste sentido, a partir das palavras de Tomás Eloy Martínez, a reflexão construída por Esteves afirma: "Hoje, poucas dúvidas restam de que ambas, história e ficção, são escritas não mais para modificar o passado, mas sim para corrigir o futuro" (ESTEVES, 2010, p. 23). A isto se pode apor as palavras do próprio autor (que também é crítico e professor universitário e não se furta, como é característica de tanto escritor contemporâneo, a emitir considerações sobre a própria obra) em um texto no qual expõe a gênese do romance. Lembrando que um romance é um tipo de texto que se realiza por meio de estruturas simbólicas, Sanches esclarece que buscou "entender o país e o personagem dentro de um conjunto de signos que se entrelaçam para compor uma narrativa que funciona num ontem que ainda é agora." (SANCHES NETO, 2012, grifo nosso).

A metaficção historiográfica, conforme visto anteriormente, permite repensar a história, bem como possibilita estabelecer analogias 
do presente com o passado e verificar quais os desdobramentos impostos pela História ao presente, comparar as mudanças mais austeras e verificar o que se repete. No ano de 2014 foi construída, em parte pelo discurso oficial, em parte pelo imaginário popular, a ideia de que esse seria o ano da grande oportunidade para o Brasil mostrar ao resto do mundo seus valores, seu potencial, dada a visibilidade que teria no cenário internacional com a realização da Copa do Mundo FIFA de Futebol (assim também deverá ser em 2016, quando da realização de um evento ainda mais abrangente, os Jogos Olímpicos). Um dos pontos altos da cerimônia de abertura do evento seria o chamado "pontapé inicial", que seria dado por um paraplégico auxiliado por um exoesqueleto biônico, invenção desenvolvida por uma equipe de mais de 150 pesquisadores de várias nacionalidades, comandados pelo neurocientista brasileiro Miguel Nicolelis. Para todos os efeitos, a demonstração inequívoca de um grande avanço científico-tecnológico que tinha como principal mentor esse brasileiro, a despeito de o projeto ter sido desenvolvido e executado fora do país (na Universidade de Duke, Durhan, Estados Unidos, talvez por aqui estar "fora das possibilidades locais", como estava a fabricação da máquina de escrever).

Amplamente divulgado pela mídia nacional, a visão de um paraplégico que se levantaria de sua cadeira e chutaria a bola fez crer a todos que se trataria de um momento solene e de glória nacional. Com benevolência, sabedor de que a história se repete, o padre Francisco João de Azevedo teria se lembrado do desdém com que tanta vez foram tratados ele e sua máquina, se pudesse ter visto os dois displicentes segundos (!) que foram reservados na transmissão oficial de TV à máquina de Nicolelis durante o evento de abertura da Copa. Como a máquina taquigráfica que não teve espaço no navio que levou os principais produtos brasileiros do século XIX (madeiras e ferramentas agrícolas) para serem expostos em Londres, a invenção de Nicolelis também foi preterida, pois faltaria espaço na transmissão de TV para mostrar ao mundo OS VERDADEIROS PRODUTOS DA INDÚSTRIA NACIONAL CONTEMPORÂNEA (ou os estereótipos a que são associados o Brasil e o brasileiro): uma série de coreografias mistificando os costumes de nosso povo - folclore gratuito e vazio (sob a responsabilidade de um italiano, diga-se de passagem).

Por outro ângulo: os padres Francisco João de Azevedo do início do século XXI, Nicolelis é apenas um exemplo, desenvolvem suas pesquisas em grandes centros de inovação e tecnologia, quase sempre fora 
do Brasil. Então, tal qual o padre, os cientistas brasileiros permanecem falando contra, escrevendo contra, enquanto são tragados pelo nosso atraso tecnológico. Neste sentido, ressalte-se, o brasileiro consome tanta tecnologia quanto as populações dos países dominantes do Ocidente. No entanto, na maioria das vezes, não inventamos tecnologia em nosso território, nem fazemos descobertas científicas significativas em nossas universidades. Se muitos pesquisadores brasileiros demonstram o tempo todo que o problema não é falta de conhecimento, o que nos falta?

Apesar das enormes diferenças sociais existentes dentro do próprio país, reduzidas infimamente nos últimos anos, temos um poderoso polo industrial, construído com tecnologia estrangeira. Será o Brasil aquele lugar que ainda inexiste com suas ideias fora do lugar? Copiamos ideias e tecnologia o tempo todo? Neste sentido, é alarmante verificar que, talvez, ainda sejamos uma colônia de exploração.

Uma resposta possível, entre muitas, estão nos dados sobre as exportações brasileiras. À época da realização da Copa do Mundo, foi divulgado que no primeiro semestre de 2014, as matérias primas haviam tomado a liderança entre os bens exportados pelo Brasil. Em 2002 apenas $25 \%$ das exportações brasileiras eram de produtos básicos (matérias-primas) e 75\% eram de bens industrializados (com destaque para combustíveis, aviões e automóveis). Em 2014 os números chegaram a $50,8 \%$ e $49,2 \%$; ligeira vantagem para as matérias-primas, cujo crescimento foi impulsionado pelo aumento da demanda da China pelo minério de ferro brasileiro. Após o início da crise financeira deflagrada nos Estados Unidos em 2009, o Brasil perdeu participação - id est, competitividade - no mercado externo, nomeadamente no que se refere aos chamados produtos de "alta intensidade tecnológica". Desde então, os analistas passaram a se preocupar com a concentração da pauta de exportações em poucos produtos primários.

Muito embora, em valores absolutos, a exportação de produtos básicos e bens industrializados salte de US\$ 7 e US\$ 22 bilhões respectivamente, em 2002, para cerca de US\$ 55 bilhões em ambos os casos em 2014, fica exposto nosso "calcanhar de Aquiles": a maior

\footnotetext{
${ }^{3}$ Todos os dados econômicos que embasam esta seção foram retirados dos seguintes sítios:

http://noticias.r7.com/economia/noticias/brasil-exporta-mais-materia-prima-emenos-produtos-de-valor-agregado-20110510.html . ACESSO EM 29/08/2014.
} 
riqueza que o país pode oferecer ao mundo é o que já havia aqui desde sempre, são riquezas brutas, "selvagens e pujantes", como diria D. Pedro II, pouco importa que seja a madeira de ontem (e de hoje) ou o minério de ferro de hoje (e de ontem). No entanto, já é possível vislumbrar no Brasil uma "tradição da ruptura"4. A expressão, retirada da poesia, funciona como uma explicação plausível para os paradoxos associados ao pensamento, à pesquisa e ao desenvolvimento brasileiro.

Se no século XIX, D. Pedro II não possuía uma tradição mínima de pesquisa, nem de ideias, figuras que resistiram, como o Padre Azevedo, criaram tal tradição em nossas terras e a perpetuaram. Ainda assim, apesar de tantos esforços e dificuldades ao longo da história, muitas vezes refuta-se tal tradição sem um necessário olhar crítico. Como visto anteriormente, a elite brasileira mal passou pela plena modernidade, no entanto, ela nos deixou marcas profundas e, por isso mesmo (além de nossa curta história), torna-se nossa tradição. Um exemplo é a crítica a tudo que é produzido em ideia e tecnologia no Brasil. O exíguo espaço de tempo reservado pela organização do mundial (e por nossa imprensa não especializada) à apresentação do Exoesqueleto foi alvo de críticas em redes sociais. O projeto "Andar de Novo", capitaneado por Miguel Nicolelis "pertence a um país que ainda não existe", mas cujo governo, ao mesmo tempo, financia o projeto com 30 milhões de dólares.

Em uma determinada perspectiva, a tecnologia, a inovação que aqui se produz, interessa menos ao mundo que a abundância do que se pode retirar in natura das nossas matas e subsolo. A máquina taquigráfica interessa menos que o jacarandá de que é feita; o exoesqueleto de Nicolelis menos que uma dança estereotipada. No entanto, o vultuoso investimento demonstra que o Estado, de alguma forma, preocupa-se com pesquisa, embora não haja dinheiro suficiente para tal. Esta afirmação

http://achadoseconomicos.blogosfera.uol.com.br/2014/07/23/em-15-anos-materiasprimas-dobram-presenca-nas-exportacoes-e-viram-maioria/ . ACESSO EM $29 / 08 / 2014$.

http://www1.folha.uol.com.br/fsp/mercado/me1107201008.htm . ACESSO EM $29 / 08 / 2014$.

4“A tradição da ruptura implica não somente a negação da tradição, como também da ruptura. . . A contradição subsiste se, em lugar das palavras interrupção ou ruptura, empregamos outra, que se oponha com menos violência às ideias de transmissão e de continuidade". (PAZ, 1984, p. 17.) 
poderia ser desconstruída em pouquíssimas palavras com outros exemplos retirados de nossas máquinas de madeira contemporâneas. No entanto, falamos contra e escrevemos contra. Vários dos teóricos utilizados aqui, bem como muitos outros em qualquer campo do conhecimento, são exemplos notórios de que pensamos contra e rompemos com uma tradição (in)existente, com ideias fora do lugar e espaços inexistentes que, paradoxalmente, já estão, em sua formação, formados. Neste sentido, Sanches Neto, a literatura brasileira contemporânea, e o romance histórico deste tempo, permanecem atentos à assertiva de Esteves (2010, p. 43) de que "os romances não são escritos para contar a vida, mas para transformá-la após o processo de leitura".

(Para o Diogo Cantarin, um brasileirinho que esperava ansiosamente para ver um robô chutar a bola, mas teve que se contentar com a Claudia Leitte)

\section{Referências}

BENJAMIN, W. Passagens. Trad. Irene Aron e Cleonice Paes Barreto Mourão e revisão de Patrícia de Freitas Camargo. Belo Horizonte/São Paulo: Editora UFMG/Imprensa Oficial do Estado de São Paulo, 2006.

BOSI, Alfredo. Post-Scriptum 1992. In: Dialética da colonização. $3^{\mathrm{a}} \mathrm{ed}$. São Paulo: Companhia das Letras, p. 347-376, 1996.

ESTEVES, Antônio Roberto. O romance histórico brasileiro contemporâneo (1975-2000). São Paulo: Edunesp, 2010.

FREUD, Sigmund. O Estranho. In: Freud. Obras completas. Edição Standard Brasileira v. XVII. Rio de Janeiro: Imago, p. 237-269, 1986.

HUTCHEON, Linda. Poética do Pós-Modernismo: história, teoria e ficção. Trad. Ricardo Cruz. Rio de Janeiro: Imago, 2002.

LUKÁCS, Gyorgy. La novela histórica. Trad. Jasmin Reuter. México: Era, 1977.

MALARD, Letícia. Romance e História. Revista brasileira de Literatura Comparada, n. 3, p. 143-50, 1996.

MILTON, Heloísa Costa. As histórias da história: retratos literários de Cristóvão Colombo. São Paulo, 1992. Tese (Doutorado) - Faculdade de Filosofia, Letras e Ciências Humanas, Universidade de São Paulo. 
PAZ, Octavio. Os filhos do barro. Trad. de Olga Savary. Rio de Janeiro: Nova Fronteira, 1984.

REGO, Enylton José de Sá. O calundu e a panacéia: Machado de Assis, a sátira menipéia e a tradição luciânica. Rio de Janeiro: Forense Universitária, 1989.

SANCHES NETO, Miguel. Réquiem para a máquina de escrever. 2012. Disponível em: http://www.blogdacompanhia.com.br/2012/11/requiempara-a-maquina-de-escrever/. Acesso em: 22 fev.2015.

SANCHES NETO, Miguel. A máquina de madeira. São Paulo: Companhia das Letras, 2012.

SANTIAGO, Silviano. Uma literatura nos trópicos. $2^{\mathrm{a}}$ ed.. Rio de Janeiro: Rocco, 2000.

SCHWARZ, Roberto. As ideias fora do lugar. In: Cultura e política. São Paulo: Paz e Terra, p. 59-84, 2005. 